\title{
CLIMATE ADAPTATION DECISION-MAKING: THE GULF COAST PHASE 2 PILOT STUDY
}

\author{
Jerald Ramsden, WSP, Jerald.Ramsden@wsp.com \\ Justin Lennon, WSP, Justin.Lennon@wsp.com \\ Benny Louie, WSP, Benny.Louie@wsp.com
}

\begin{abstract}
INTRODUCTION
The Gulf Coast Study is an initiative from the U.S. Department of Transportation's Office of Sustainability to study the projected impacts of climate change on transportation infrastructure in the Gulf Coast region. The Phase 2 portion of the Gulf Coast Study was focused on the greater Mobile, Alabama, area with the purpose of providing detailed assessments of the performance of critical infrastructure under specific climate change threats in a coastal environment. This presentation will include a discussion of the Adaptation Decision-making Assessment Process (ADAP) that was developed by WSP in conjunction with the Federal Highway Administration (FHWA), (2016). The Gulf Coast Phase 2 Pilot Study included an Engineering Analysis of Climate Change Impacts and Adaptation Measures FHWA (2014) that followed the 11-step ADAP process. The process was applied to 10 case studies. Two of these case studies are presented, highlighting application of ADAP to coastal transportation infrastructure.
\end{abstract}

\section{DECISION-MAKING PROCESS}

The ADAP is a proposed tool for planners and designers to account for the increasing role of climate change in the design of civil works projects The ADAP process was developed by the team as an example of a risk-based tool to aid decision-makers in determining which project alternative makes the most financial sense in terms of life cycle cost when considering shifting future climate conditions. ADAP provides a framework for generating the information needed to identify preferred approaches to project design based upon costs and benefits. The process was developed to help design practitioners bridge the gap between existing engineering practices and shifting climate conditions. ADAP was designed by the team to be general enough to apply to the entire spectrum of climate-influenced infrastructure.

The 11 steps of ADAP are:

1) Understand the site context

2) Document existing or future base case facility

3) Identify climate stressors

4) Develop climate scenarios

5) Assess facility performance

6) Develop adaptation options

7) Assess performance of the adaptation option

8) Conduct an economic analysis

9) Evaluate additional considerations

10) Select a course of action

11) Develop a facility management plan

The ADAP is not intended to change specific design methodologies. What the process potentially does change are the climate-related inputs used in the design methodology, the number and type of design options developed, and how the final option is selected to provide a cost-effective and resilient improvement to the transportation infrastructure.

\section{CASE STUDIES}

Ten pilot case studies were analyzed in the Gulf Coast Phase 2 Engineering Analysis, FHWA (2014), including a culvert, freeway overtopping, bridge, bridge approach causeway, bridge abutment, an elevated freeway ramp, freeway tunnel, pile-supported pier at a port, and pavement mix design. Two of these case studies are discussed further in this presentation, including the freeway ramp and freeway overtopping.

The freeway ramp case study involves the analysis of sea level rise and intensified coastal storm surge impacts on the design of a ramp bridge connecting Interstate 10 and Battleship Parkway (U.S. 98). In this study, a detailed engineering analysis was performed to determine if the bridge would fail in any of three modes, including (1) wave-induced uplift and associated displacement of the superstructure, (2) lateral-loading-induced failure of the substructure, or (3) scour-induced failure of the substructure. Three storm scenarios were included in the analysis. All three scenarios are based on Hurricane Katrina, including Hurricane Katrina Base Case (as occurred in Mobile); Hurricane Katrina Shifted to make land fall in Mobile; and Hurricane Katrina Shifted, Intensified and including Sea Level Rise (with a 14\% reduction in central pressure and 2.5 feet $[0.8 \mathrm{~m}$ ] of sea level rise). The analysis was based on the American Association of State Highway and Transportation Officials (AASHTO) Guides Specifications (2008) and (2012). The study included analysis of multiple schemes for adapting the bridge structure to improve resiliency, including designing the bridge superstructure to break away to prevent damage to the substructure, strengthening bolt connections, installation of open grid decks, use of shallower girder sections, using open rail parapets, and shortening the bridge and replacing the lower bents with protected embankment.

Findings from the ramp bridge analysis indicate the bridge section considered is not likely vulnerable to Failure Mode 1 , but could be vulnerable to Failure Mode 2 and Mode 3. This vulnerability was illustrated by Hurricane Katrina, which dislodged the deck and girders of the ramp 6 feet (1.8 meters) to the north, Cuomo et. al. (2009). An interesting finding of the study is that the worst-case storm scenario did not necessarily translate into the worst effects on the facility, as a condition developed where overtopping of the bridge for higher surge levels reduced the slamming forces of wave impact and the scour effects. 
Retreat was also identified as a possible option for consideration depending on a cost-benefit analysis of doing so.

The freeway overtopping case study focused on a segment of I-10 southwest of Mobile. At this study site, a 10-lane portion of the freeway was adjacent to the Mobile Bay flood zone. This study presents a case that included detailed investigations into the coastal storm surgeinduced overtopping of the interstate and surrounding topography. The case study utilized Advanced Circulation (ADCIRC) modeling results developed for the Gulf Coast project, which analyzed Hurricane Georges and Hurricane Katrina. Modified and intensified versions of Katrina, described above, were also investigated to determine the impacts of possible future hurricane scenarios on the Interstate. Time-step analyses of the storm surge scenarios were performed to evaluate impacts such as potential breaching of the interstate, erosive forces along underpasses and flooding of the surrounding neighborhoods. The potential for overtopping was evaluated by overlaying the projected surge flood elevations on to the roadway profile and cross sections of the underpasses. Failure (breaching) of the roadway was evaluated by modeling the road as a barrier across the flow and calculating erosion potential and erosion rates based on estimated flow rates. The potential and degree of inland flooding of the nearby Oakdale neighborhood was determined using a time-step analysis and the storm surge hydrographs. Then the maximum flow velocity through the bridge underpasses were estimated using a FHWA tidal hydraulic orifice approach combined with time step analysis of the storm surges.

The segment of interstate analyzed was concluded to have the potential to overtop and be vulnerable to erosion under certain storm scenarios. Viable adaptation options include hardening the underpasses, armoring the roadway embankment, and raising the roadway.

\section{CONCLUSIONS}

The Gulf Coast Phase 2 Pilot Study Engineering Analysis, FHWA (2014), included a summary of lessons learned for both the ADAP process and the case studies, as well as a list of research needs. These will be provided in the presentation.

Climate change and associated adaptation strategies is an active area of research. Subsequent studies completed by the FHWA and others will be mentioned in the presentation.

\section{REFERENCES}

American Association of State Highway and Transportation Officials (2008), Guide Specifications for Bridges Vulnerable to Coastal Storms. American Association of State Highway and Transportation Officials. Washington, DC.
American Association of State Highway and Transportation Officials (2012), LRFD Bridge Design Specifications (6th ed.). American Association of State Highway and Transportation Officials. Washington, DC.

Cuomo, Shimosako, and Takahashi (2009), Wave-in Deck Loads on Coastal Bridges and the Role of Air. Coastal Engineering 56:793-809.

U.S. Department of Transportation, Federal Highway Administration (2012), Gulf Coast Study, Phase 2 - Task 2: Climate Variability and Change in Mobile, Alabama. Report No.: FHWA-HEP-12-053, September, 2012.

U.S. Department of Transportation, Federal Highway Administration (2014), Gulf Coast Study, Phase 2 - Task 3.2: Engineering Analysis and Assessment. Report No.: FHWA-HEP-15-004, August, 2014.

U.S. Department of Transportation, Federal Highway Administration (2016), TEACR Engineering Assessment Adaptation Decision-making Assessment Process (ADAP), Publication FHWA-HEP-17-004, September, 2016. 